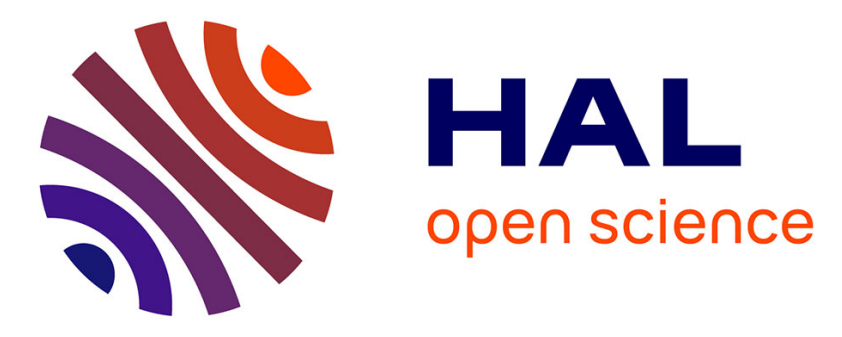

\title{
Multijunction solar cell mesa isolation: Correlation between process, morphology and cell performance
}

\author{
Mathieu de Lafontaine, Farah Ayari, Erwine Pargon, Guillaume Gay, Camille
}

Petit-Etienne, Artur Turala, Gwenaelle Hamon, Abdelatif Jaouad, Maité

Volatier, Simon Fafard, et al.

\section{To cite this version:}

Mathieu de Lafontaine, Farah Ayari, Erwine Pargon, Guillaume Gay, Camille Petit-Etienne, et al.. Multijunction solar cell mesa isolation: Correlation between process, morphology and cell performance. Solar Energy Materials and Solar Cells, 2022, 239, pp.111643. 10.1016/j.solmat.2022.111643 . hal03582886

\section{HAL Id: hal-03582886 \\ https://hal.science/hal-03582886}

Submitted on 21 Feb 2022

HAL is a multi-disciplinary open access archive for the deposit and dissemination of scientific research documents, whether they are published or not. The documents may come from teaching and research institutions in France or abroad, or from public or private research centers.
L'archive ouverte pluridisciplinaire HAL, est destinée au dépôt et à la diffusion de documents scientifiques de niveau recherche, publiés ou non, émanant des établissements d'enseignement et de recherche français ou étrangers, des laboratoires publics ou privés. 


\title{
Multijunction Solar Cell Mesa Isolation: Correlation Between Process, Morphology and Cell Performance
}

\author{
Mathieu de Lafontaine ${ }^{\mathrm{a}, \mathrm{b}, \mathrm{c}}$, Farah Ayari ${ }^{\mathrm{a}, \mathrm{b}}$, Erwine Pargon $^{\mathrm{c}}$, Guillaume \\ Gay $^{\mathrm{c}}$, Camille Petit-Etienne ${ }^{\mathrm{c}}$, Artur Turala ${ }^{\mathrm{a}, \mathrm{b}}$, Gwenaelle Hamon ${ }^{\mathrm{a}, \mathrm{b}}$, \\ Abdelatif Jaouad $^{\mathrm{a}, \mathrm{b}}$, Maïté Volatier ${ }^{\mathrm{a}, \mathrm{b}}$, Simon Fafard ${ }^{\mathrm{a}, \mathrm{b}}$, Vincent Aimez ${ }^{\mathrm{a}, \mathrm{b}}$, \\ Maxime Darnon ${ }^{\mathrm{a}, \mathrm{b}}$ \\ ${ }^{a}$ Laboratoire Nanotechnologie Nanosystèmes (LN2) - CNRS IRL-3463, Université de \\ Sherbrooke, 3000 Boulevard Université, Sherbrooke, J1K OA5, Québec, Canada \\ ${ }^{b}$ Institut Interdisciplinaire d'Innovation Technologique (3IT), Université de Sherbrooke, \\ 3000 Boulevard Université, Sherbrooke, J1K OA5, Québec, Canada \\ ${ }^{c}$ Université Grenoble Alpes CNRS, CEA/LETI- Miantec, Grenoble INP, LTM, 17 \\ avenue des Martyrs, F-38054 Grenoble, Grenoble, France
}

\section{Abstract}

Multijunction solar cells must be electrically isolated from one to another at the end of the fabrication process; a step known as mesa isolation. In this study, three different techniques are assessed to perform this step: saw-dicing, wet etching and plasma etching. Triple junction solar cells were fabricated with each process and the open-circuit voltages were measured in order to compare the impact of each technique on the device performance. An optional wet treatment is also proposed to clean the sidewalls after the mesa isolation process. The mesa sidewalls were characterized by scanning electron microscopy and atomic force microscopy to assess the profile length and roughness respectively. The cell performance was then correlated to the sidewall length and roughness for all three isolation techniques. This study indicates that a plasma etching process followed by a wet clean is the process that maximizes the solar cell performance, thanks to a short profile length 
and a low sidewall roughness.

Keywords:

Plasma etching, Mesa Isolation, Concentrated photovoltaics, Multijunction solar cells, III-V, Plasma etching, Wet etching, Saw dicing

\section{Introduction}

As hundreds of multijunction solar cells can be fabricated from a single wafer, each component must be electrically isolated from one to another, at the end of the fabrication cycle. This step is commonly referred as mesa isolation and it can be performed by saw-dicing [de Lafontaine et al. (2021a); de Lafontaine et al. (2016)], wet etching [Kim et al. (2014); Raappana et al. (2021); Bennett et al. (2015); de Lafontaine et al. (2021a); Malevskaya et al. (2019); Turala et al. (2013); Geisz et al. (2020); Helmers et al. (2011)] or plasma etching [Raappana et al. (2021); Albert et al. (2021); de Lafontaine et al. (2021a); de Lafontaine et al. (2016); Lafontaine et al. (2019); de Lafontaine et al. (2021b)]. Saw-dicing relies on physical abrasion, wet etching uses chemical reaction and plasma etching uses a combination of chemical reactions and ion-assisted sputtering to consume the target material. In the two latter cases, the chemistry must be chosen adequately to etch multijunction solar cells (III-V semiconductor compounds and Ge for a III-V/Ge triple junction solar cells). Wet mesa etching can be performed with variety of different solutions such as $\mathrm{H}_{3} \mathrm{PO}_{4} / \mathrm{H}_{2} \mathrm{O}, \mathrm{HCl} / \mathrm{H}_{3} \mathrm{PO}_{4}, \mathrm{H}_{2} \mathrm{SO}_{4} / \mathrm{H}_{2} \mathrm{O}_{2} / \mathrm{H}_{2} \mathrm{O}$ and $\mathrm{H}_{2} \mathrm{O}_{2}$ [de Lafontaine et al. (2021a)], $\mathrm{K}_{2} \mathrm{Cr}_{2} \mathrm{O}_{7} / \mathrm{HBr}$ and $\mathrm{KOH} /$ glycerol [Malevskaya et al. (2019)], $\mathrm{Br}_{2} / 2$-propanol and $\mathrm{H}_{2} \mathrm{O}_{2}$ [Turala et al. (2013)], $\mathrm{HBr} / \mathrm{Br} / \mathrm{H}_{2} \mathrm{O}$ [Geisz et al. (2020)], $\mathrm{H}_{3} \mathrm{PO}_{4} / \mathrm{H}_{2} \mathrm{O}_{2} / \mathrm{H}_{2} \mathrm{O}$ and $\mathrm{HBr} / \mathrm{H}_{3} \mathrm{PO}_{4}$ [Helmers et al. 
(2011)]. Plasma mesa etching can be performed with different chlorine-based chemistries such as $\mathrm{BCl}_{3} / \mathrm{Cl}_{2}$ [de Lafontaine et al. (2016); Lafontaine et al. (2019)], $\mathrm{SiCl}_{4} / \mathrm{Cl}_{2}$ [Lafontaine et al. (2019)] and $\mathrm{SiCl}_{4} / \mathrm{H}_{2}$ [de Lafontaine et al. (2021a,b)] as most chlorine-based subproducts from III-V semiconductors etching are volatile $\left(\mathrm{GaCl}_{x}, \mathrm{AsCl}_{x}\right.$, etc), with the exception of $\mathrm{InCl}_{x}$ at room temperature. In this case, desorption can be stimulated by energetic ion bombardment.

The solar cell performance is affected by recombinations at the sidewalls of the cells (perimeter recombination) [de Lafontaine et al. (2021a); EspinetGonzalez et al. (2014); Belghachi and Khelifi (2006)]. Understanding these mechanisms is especially important considering the fact that the performance loss increases when the cell dimension is reduced towards the submillimetric range needed for micro-concentrator photovoltaics (Micro-CPV) [EspinetGonzalez et al. (2014); Belghachi and Khelifi (2006); Albert et al. (2021); Wiesenfarth et al. (2020)]. One can expect the cell performance to depend on the sidewall fabrication method, herein, the mesa isolation etching. A comparative study between all three techniques has previously shown that plasma etching followed by a wet clean can maximize the device open-circuit voltage on III-V/Ge triple junction heterostructures [de Lafontaine et al. (2021a)]. Despite the improvement provided by plasma etching, the underlying mechanisms and the morphological characteristics of mesa isolation and their impact on III-V/Ge solar cell performance have yet to be investigated. Therefore, identifying the critical mesa isolation characteristics and the optimization pathways represent the keystone for the development of smaller 
$\left(<200 x 200 \mu \mathrm{m}^{2}\right)$ micro-multijunction solar cells for Micro-CPV applications [Albert et al. (2021); Dominguez et al. (2017); Wiesenfarth et al. (2020)]. In this study, III-V/Ge triple junction solar cells were fabricated with the three different mesa isolation techniques and their open-circuit voltages were assessed under AM1.5D illumination. The sidewall profiles were characterized by scanning-electron microscopy (SEM) and the sidewall roughness was assessed by atomic force microscopy (AFM). Lastly, the open-circuit voltages were then correlated to the sidewall profile and roughness in order to identify the important mechanisms and characteristics to consider when choosing the proper mesa isolation process.

\section{Experiments}

A commercial quantum-dot-enhanced III-V/Ge triple junction heterostructure with an InGaP top, an (In)GaAs middle cell and a Ge bottom cell was used as the starting epiwafer (fig. 2a) [Fafard (2001)]. All the samples were processed from the same epiwafer to reduce the performance variability associated to the active regions. All the processing steps were identical for all samples, with the exception of mesa isolation, to enable us to directly study the impact of the mesa sidewalls on the device performance. Fig. 1 presents a SEM image of the III-V epitaxy and the upper region of the Ge substrate [de Lafontaine et al. (2021b)]. Fig. 2 (taken from [de Lafontaine et al. (2021a)]) presents the main steps performed to fabricate the samples used in this study.

A Ni/Ge back contact was deposited by evaporation (fig. 2 b). Then, the front contact was patterned by photolithography, Ni/Ge/Au/Ni/Au evapo- 


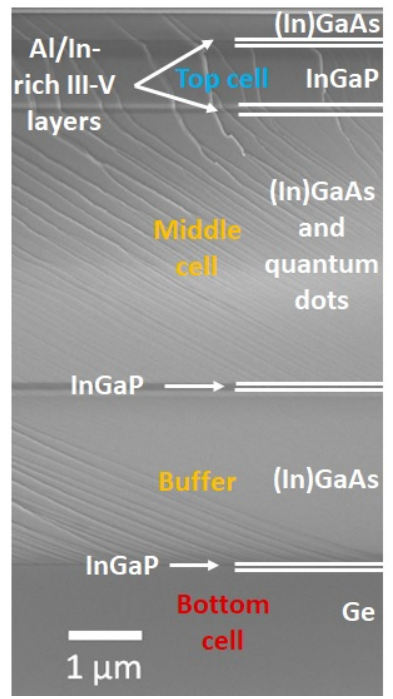

Figure 1: Cross-section scanning-electron microscope image of the III-V/Ge heterostructure [de Lafontaine et al. (2021b)].

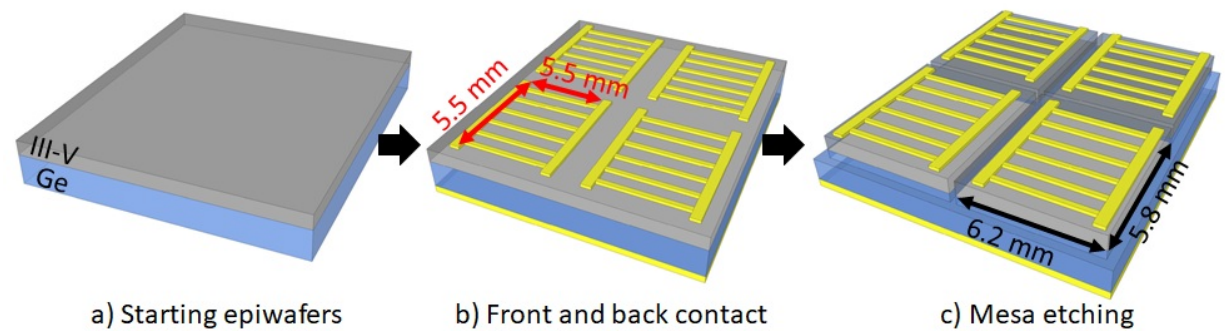
metallization

Figure 2: Schematics of the microfabrication process consisting in a) the starting III-V/Ge epiwafers, b) the front and back metallization and c) the mesa isolation step performed by saw dicing, wet etching or plasma etching. [de Lafontaine et al. (2021a)]

ration and lift-off (fig $2 \mathrm{~b}$ ). The grid lines and busbars defined a $5.5 \times 5.5 \mathrm{~mm}^{2}$ active area format as shown in fig $2 \mathrm{~b}$. The components are then electrically isolated by mesa isolation (fig. 2c). For this step, $100 \mu \mathrm{m}$-wide trenches were etched by the three different methods we aim to compare: saw-dicing, 
plasma etching and wet etching. This step defined $5.8 \times 6.2 \mathrm{~mm}^{2}$ mesas as shown in fig. 2c. This choice enabled to obtain solar cells with an identical perimeter-to-area ratios $\left(\frac{P}{A}\right)$ of $\sim 7 \mathrm{~cm}^{-1}$, in order to rigorously assess and compare perimeter-related effects that were induced by all three techniques. A large surface can damper the effects of under-etching and will alter less the $\frac{P}{A}$, which would not be the case for micro-scale solar cells. This is the reason why millimetric cells were chosen for this study, instead of micro solar cells. This characteristic is required as this study aims to assess the sidewall morphology and the mesa isolation process more than the $\frac{P}{A}$ effects. Sawdicing mesa isolation was performed with the R07-BB200 diamond blade made by Disco. This blade is $100 \mu \mathrm{m}$-wide and it is exclusively used on III$\mathrm{V}$ compounds and Ge. For both wet- and plasma-etched samples a second photolithography step was used to pattern the $100 \mu \mathrm{m}$-wide trenches. This width is solely chosen to match the $100 \mu$ m-wide diamond blade in order to keep the $\frac{P}{A}$ between each samples. Reducing trench width to $10 \mu \mathrm{m}$ by plasma etching is easily possible and could reduce the epiwafer area losses [de Lafontaine et al. (2021a)].

The wet mesa etching consists in a succession of $\mathrm{H}_{3} \mathrm{PO}_{4}(86 \%): \mathrm{H}_{2} \mathrm{O}(1: 5)$, $\mathrm{HCl}(38 \%): \mathrm{H}_{3} \mathrm{PO}_{4}(86 \%)$ (4:1) and $\mathrm{H}_{2} \mathrm{SO}_{4}(96 \%): \mathrm{H}_{2} \mathrm{O}_{2}(30 \%): \mathrm{H}_{2} \mathrm{O}(1: 10: 20)$ solutions at room temperature to etch the III-V epitaxial layers. $\mathrm{HCl}$ and $\mathrm{H}_{3} \mathrm{PO}_{4}$ targeted III-P materials and $\mathrm{H}_{2} \mathrm{SO}_{4}$ aimed to etch III-As materials. $\mathrm{H}_{2} \mathrm{O}_{2}(30 \%)$ heated to $50^{\circ} \mathrm{C}$ was used to etch the Ge bottom cell. These were chosen, rather than bromine chemistries, as they do not alter much the photoresist mask. While a bromine-based chemistry would have enabled a 
non-selective etch similar to plasma etching and saw dicing, it would have reduced the overall process throughput because of the hard mask requirement. Indeed, it was shown that with bromine-based solutions a $\mathrm{SiO}_{2}$ hard mask is necessary [Turala et al. (2013)], which adds supplementary processing steps. In the scope of this study, we chose to keep a similar throughput for all techniques, in order to make it industrially relevant. The plasma mesa etching was performed by using a $\mathrm{SiCl}_{4} / \mathrm{H}_{2}$ plasma at room temperature [de Lafontaine et al. (2021b)]. The photoresist was stripped with an $\mathrm{O}_{2}$ plasma and solvents after mesa etching. The plasma-etched samples were also dipped into $\mathrm{HF}$ in order to strip the $\mathrm{SiO}_{x} \mathrm{Cl}_{y}$ inhibiting layer of the sidewalls [de Lafontaine et al. (2021b)]. Furthermore, the mesa sidewalls that were saw-diced and plasma-etched could also be cleaned by an optional $\mathrm{NH}_{4} \mathrm{OH} / \mathrm{H}_{2} \mathrm{O}_{2} / \mathrm{H}_{2} \mathrm{O}$, which will slightly etch the (In)GaAs middle cell and the Ge bottom cell, but not the InGaP top cell. This step is performed concurrently with the contact layer etching, that can be done either before or after the mesa isolation. From a manufacturing standpoint, wet cleaning the sidewalls or not does not alter the processing time as it is only a matter of process sequence. Indeed, if the contact layer etch is performed after mesa isolation, the mesa sidewalls will be wet cleaned (later refered as "plasma etched + wet clean" or "saw diced + wet clean"). Conversely, if the contact layer etching is performed before the mesa isolation, no wet clean will occur (later referred as "plasma etched", "saw diced" or "wet etched"). For wet etch, the wet clean is embedded in the etch sequence. Therefore, five solar cell types were fabricated and compared: (1) saw-diced, (2) saw-diced + wet clean, (3) plasma-etched, (4) plasma-etched + wet clean and (5) wet etched. At least two solar cells of each 
type were fabricated. In this study, no antireflection coating was deposited on the solar cells, even though it could passivate surfaces. The open-circuit voltage $\left(\mathrm{V}_{o c}\right)$ of the solar cells were measured under 1-sun AM1.5D illumination, as it is a parameter that is sensitive to surface recombination. Then, the average value and standard variation for each mesa isolation technique are assessed. The mesa trench profile was observed by scanning electron microscopy. Finally, the mesa sidewall roughness was assessed by tilted atomic force microscopy (AFM) [Fouchier et al. (2013)]. For comparison purposes, the roughness was calculated from identical projected areas between each sample.

\section{Results}

\subsection{Solar cell performance}

Fig. 3 presents the average $\mathrm{V}_{o c}$ obtained for each mesa isolation technique. The error bars consist in the standard deviation obtain from all the solar cells fabricated for each mesa isolation technique. First, one can observe that this uncertainty coming from the process reproductibility is below the variation from the mesa isolation technique. All mesa isolation techniques present a similar $\mathrm{V}_{o c}$ of $\sim 2.45 \pm 0.02 \mathrm{~V}$ with the exception of saw-dicing, which has a lower value $(2.19 \mathrm{~V})$. This can be explained by the harsh and physical nature of the technique. However, it is possible to notice that the opencircuit voltage is increased once a wet clean is performed on both the sawdiced and plasma-etched solar cell. Furthermore, after the wet clean, both the saw-diced and the plasma-etched solar cells generate a higher $\mathrm{V}_{o c}$ than the wet-etched samples, which suggests that a clean sidewall is only one of 


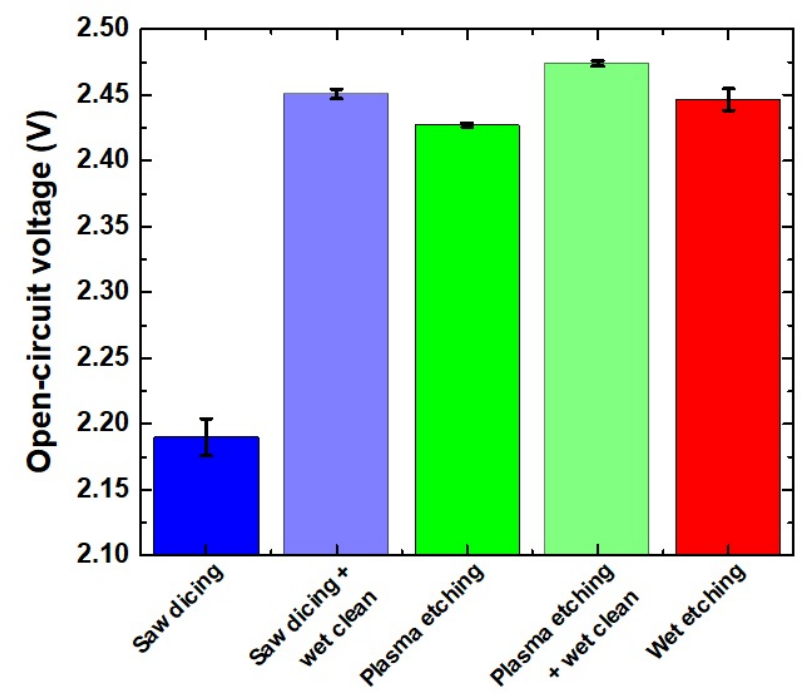

Figure 3: Average 1-sun AM1.5D open circuit voltage of III-V/Ge triple junction solar cell obtained from five different mesa isolations. The error bars consist in the standard deviation obtained from all the solar cells fabricated for each mesa isolation.

several characteristics to consider when optimizing the mesa isolation step. A first hypothesis is that each technique will not present the same sidewall profile, which will alter the total sidewall surface, and therefore, the total edge recombination. A second hypothesis is that each technique will cause different roughnesses on the sidewall, which will alter the developed area, and therefore, the total perimeter recombination. The following two sections will respectively address these two hypotheses.

\subsection{Sidewall profile}

The sidewall morphology has been studied and fig. 4 presents crosssection scanning electron microscope images of the mesa isolation sidewall for all five techniques. Plasma-etched sidewalls (fig. 4a) are steep and have a limited sidewall erosion. The ion-assisted sputtering combined with the forma- 


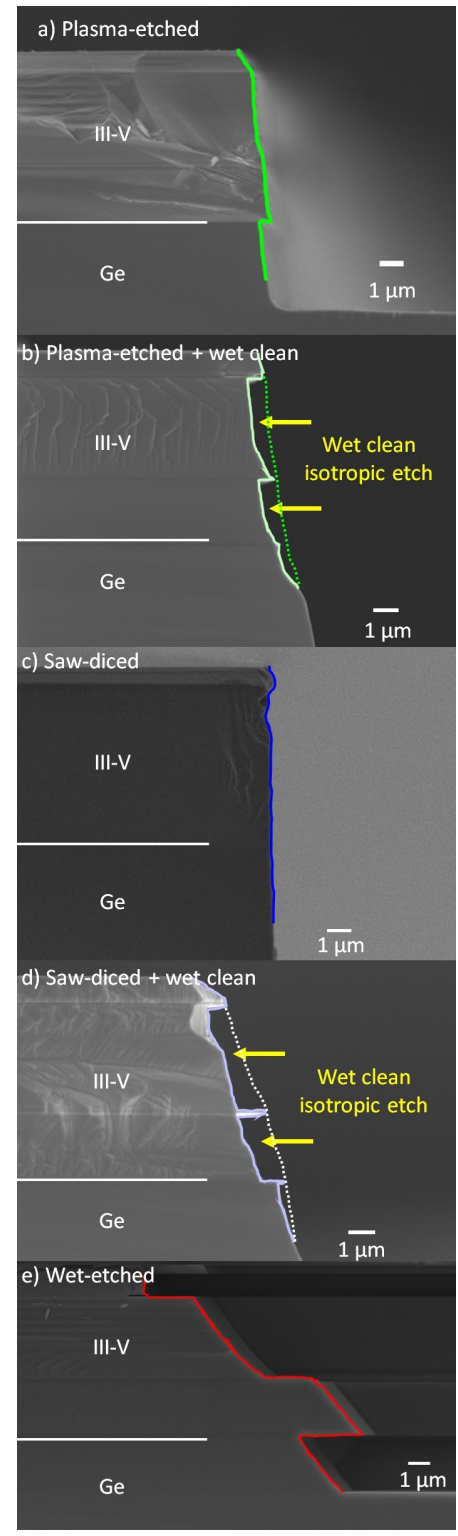

Figure 4: Cross-section scanning electron microscope images of the mesa isolation sidewall performed by a) plasma etching, b) plasma etching + wet clean, c) saw-dicing, d) sawdicing + wet clean and e) a wet-etching. The dotted lines represent the expected profile before the wet clean. 
tion of a $\mathrm{SiCl}_{x}$ etch-inhibiting layer on the sidewalls explains the anisotropic profile [de Lafontaine et al. (2021b)]. After the wet clean, the plasma-etched sidewall is slightly isotropically etched, mostly in (In)GaAs middle cell and buffer and a little bit in the Ge, as shown in fig. 4b. A similar behavior can be observed on the saw-diced (fig. 4c) and the saw-diced + wet clean samples (fig. 4d). The saw diced sidewall are vertical, thanks to the diamond blade. The wet clean selectively under-etch the (In)GaAs in the vicinity of both the middle cell and buffer layers, creating the slight under-etch presented in fig. 4d. The sidewall profile loses completely its verticality for a complete wet-etched isolation (fig. 4e). In this case, the succession of several isotropic wet processes creates a slanted sidewall with several under-etched layers. The isotropic and anisotropic behaviors will respectively increase or decrease the sidewall profile in the junction vicinity. One could believe that as the total sidewall length increases, so will the total perimeter recombination since, assuming a constant defect density on the sidewalls, there will be more non-radiative defects. Fig. 5 presents the open-circuit voltages as a function of the total sidewall length for each technique. However, only the sidewalls in the vicinity of all three junctions are expected to alter the open-circuit voltage. Therefore, the total sidewall length was calculated as the developed sidewall length from the front side of the solar cell, down to 2 $\mu \mathrm{m}$-deep in the Ge substrate, for each mesa isolation technique, regardless of the real mesa depth. The open-circuit voltage does not decrease with increasing sidewall length, which suggests other factors must be taken into account. Indeed, despite the fact the wet-etching results in a sidewall length of $20 \mu \mathrm{m}$, it presents one of the highest $\mathrm{V}_{o c}$. Conversely, saw-dicing presents vertical 
sidewalls (fig. 4c), which results in the shortest sidewall profile length but the device has the lowest $\mathrm{V}_{o c}$. Furthermore, despite the fact that the plasmaetched sidewall and the plasma-etched + wet clean sidewalls have a similar sidewall profile length, their $\mathrm{V}_{o c}$ are different. These characteristics suggest that sidewall profile length can not entirely explain the $\mathrm{V}_{o c}$ changes from one technique to another.

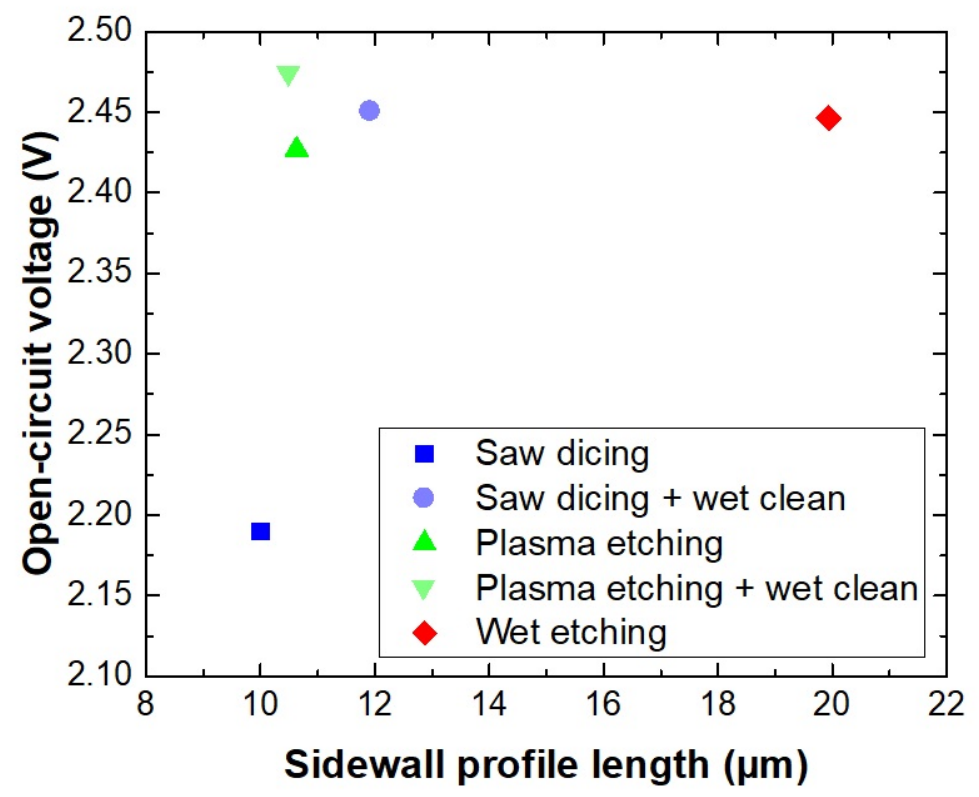

Figure 5: Open-circuit voltage of III-V/Ge triple junction solar cells as a function of the sidewall profile length in the vicinity of the junctions for each mesa isolation technique.

\subsection{Sidewall roughness}

It is possible to generalize the edge recombination dependence with sidewall length by assessing the sidewall topography. For this purpose, atomic 
force microscopy measurements were performed on the sidewall. A rough surface should increase the total sidewall surface area, and thus, also increase the total number of defects on the sidewall. The root mean squared (RMS) roughness is usually assessed for this purpose. However, this value scales with the different height variations from a reference plane but it is not as suited to assess the total effective area. In this purpose, the developed area ratio (Sdr) is studied instead. The developed area ratio is defined as the percentage of the additional surface area created from the roughness compared to the planar projected area, as shown in the following equation:

$$
\operatorname{Sdr}=\frac{A_{d}-A_{p}}{A_{p}}
$$

In this equation, $A_{d}$ is the developed area and $A_{p}$ is the projected area. The developed area ratio of the sidewall surface and the root mean squared roughness (RMS) were assessed for each mesa isolation technique, with the exception of the wet etch process. As shown in fig 4e, the under-etch is too large, which makes it impossible to obtain a decent sidewall roughness value by AFM. The developed area ratio of the sidewall surface and the root mean squared roughness were independently assessed in the vicinity of the top cell $\left(\operatorname{Sdr}_{T C}\right.$ and $\left.\mathrm{RMS}_{T C}\right)$, the middle cell $\left(\operatorname{Sdr}_{M C}\right.$ and $\left.\mathrm{RMS}_{M C}\right)$, and the bottom cell $\left(\mathrm{Sdr}_{B C}\right.$ and $\left.\mathrm{RMS}_{B C}\right)$. Fig. 6 presents profile reconstructed by AFM [Fouchier et al. (2013)] and Sdr measurements performed on a plasma-etched sidewall (fig. 6a), plasma-etched + wet clean sidewall (fig. 6b), saw-diced sidewall (fig. 6c) and saw-diced + wet clean sidewall (fig. 6d). Plasma etching creates low roughness sidewalls as the $\mathrm{Sdr}$ is limited to $3.9 \%$ in the vicinity of the top cell and it drops to $2.3 \%$ deeper down the heterostructure 
( $\mathrm{MC}$ and $\mathrm{BC})$, as shown in fig. 6a.

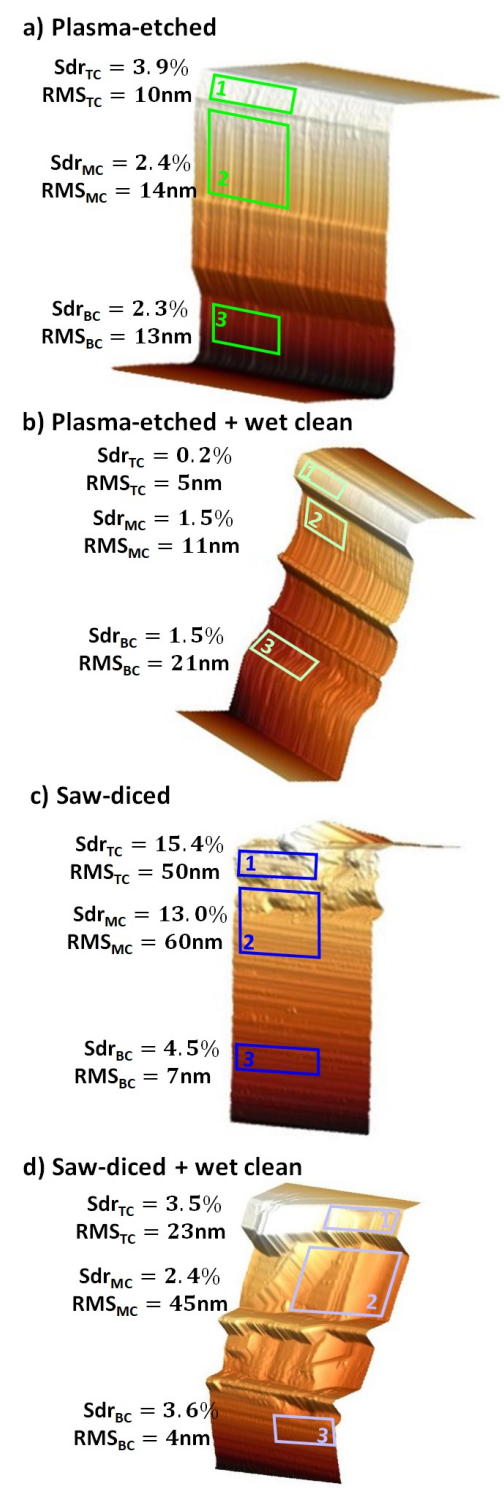

Figure 6: AFM images performed on the sidewall of a mesa isolation by (a) plasma-etching, (b) plasma-etching + wet clean, (c) saw-dicing and (d) saw-dicing + wet clean. Both Sdr and RMS are assessed over the top cell (region 1), the middle cell (region 2) and the bottom cell (region 3) sidewalls. 
This roughness variation can be explained by the different etching mechanisms involved in each subcells. First, the top cell is rich in indium $(\sim 25$ \%), which forms non-volatile sub-products in chlorine-based plasmas $\left(\operatorname{InCl}_{x}\right)$. This region relies heavily on the physical sputtering of the non-volatile compounds and it can explain why the roughness is more important. Furthermore, this region is right under the mask and the tapered profile is susceptible to be eroded because of mask faceting. The last two subcells can be chemically etched in a chlorine-based plasma that does not rely as much on the physical sputtering. As shown in fig. 6b, the introduction of a wet clean after the plasma etching step reduces the sidewall roughness down to a Sdr of 0.2 $\%$ for the top cell and $1.5 \%$ for the middle and bottom cells. Despite the fact that the wet clean does not etch the top cell, it can still slightly reduce its roughness. Therefore, performing the contact layer etch after the mesa isolation enables to smoothen the sidewall in the vicinity of all the junctions.

Fig. 6c presents an AFM image of a saw-diced sidewall. As expected, the roughness is larger for this technique as it ranges from an Sdr of $15.4 \%$ for the top cell to an Sdr of $4.5 \%$ for the bottom cell. The high roughness in the upper heterostructure (top cell and upper middle cell) can be explained by micro-fractures. The blade damage combined with the abrupt crystal discontinuity and the corner-shaped morphology in the upper mesa sidewall can facilitate dislocation of micrometric semiconductor fragments and it explains why there is a higher roughness in this region. Fortunately, the wet clean enables to smoothen the saw-diced sidewall to an Sdr ranging between $2.4 \%$ and $3.6 \%$ as shown in fig. 6d. However, these values are 
still higher than those from the plasma-etched + wet clean technique. It can be explained by the micro-fractures created from the diamond blade. The wet clean solution can insert into the micro-fractures and it creates localized sidewall erosion in this vicinity, which enhances the sidewall topography, as shown in fig $6 \mathrm{~d}$. This shows that, despite the smoothing effect of the wet clean, micro-fractures from saw-dicing can not be fully restored to a smooth sidewall like plasma-etching. It will only reduce the high spatial frequency roughness down to a low spatial frequency roughness.

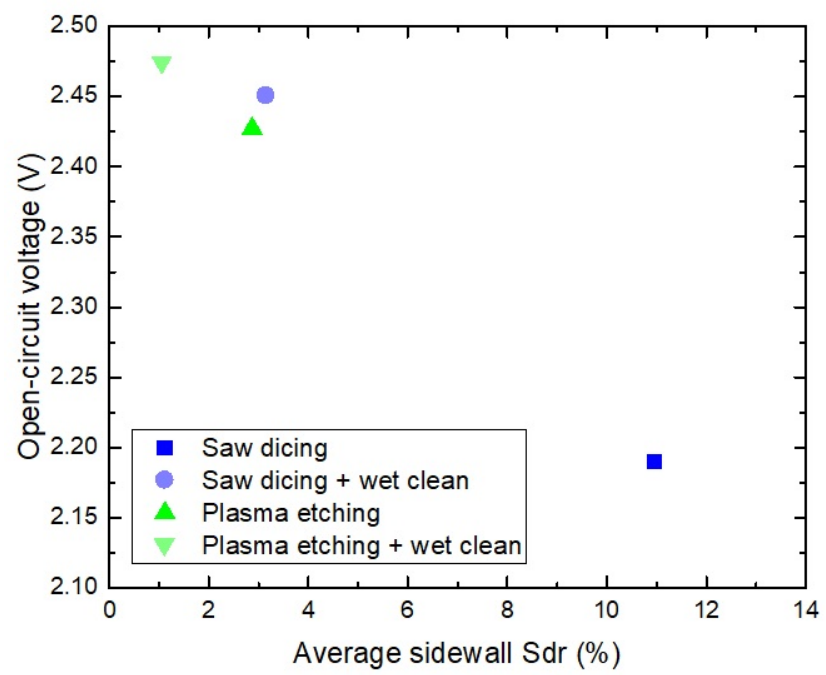

Figure 7: Open-circuit voltage as a function of the average sidewall Sdr roughness after a mesa isolation performed by plasma-etching, plasma-etching + wet clean, saw-dicing and saw-dicing + wet clean.

Fig. 7 presents the open-circuit voltage as a function of the average sidewall Sdr roughness. As a general trend, one can observe that the open-circuit voltage decreases as the developed area ratio increases. This behavior is in agreement with the fact that a larger sidewall surface area will increase the 
total edge recombination and thus, reduces the device performance. It confirms that only considering the sidewall length is not enough to assess the origin of the performance variation from one technique to another and that the developed surface must be considered. Performing the contact layer etching after mesa isolation (adding a wet clean) enables to reduce the sidewall roughness, which increases the open-circuit voltage. It must be noted that while these characteristics are correlated by the fact that decreasing the total area reduces the total edge recombination, the wet clean can also enhance the performance through another mechanism. For example, it can remove plasma etching-based defects such as chlorine [de Lafontaine et al. (2021b)] or contaminations from the saw-dicing blade. Separating these two effects is not an easy task and would require a methodology that is beyond the scope of this study.

Another interesting point is that the wet clean process can not restore the performance and reduce the sidewall roughness on the saw-diced samples as much as plasma-etched samples. This can be explained by the fact that saw-dicing induces microfractures as shown in fig. 6c. As a matter of fact, it is possible that several micro fractures can not be observed by AFM as the topography probed depends on the tip morphology. The micro-fractures may have high aspect ratios that prevent to be properly probed. The Sdr associated to saw-dicing are therefore undervalued at best. Consequently, the wet clean has a limited impact, as it will only smoothen the high frequency roughness (estimated to $2 \pm 1 \mu \mathrm{m}^{-1}$ ) down to a low frequency roughness (estimated to $0.2 \pm 0.1 \mu \mathrm{m}^{-1}$ ), as shown in fig. 6c and d. Since plasma etching 
does not create micro-fractures, it naturally presents the smoothest sidewalls after the wet clean, and therefore, the best performance.

\section{Discussion}

In the previous sections, several performance-altering mechanisms such as isotropic etching, the formation of rough sidewalls and sidewall contamination related to mesa isolation were identified. However, depending on the technique, some of them are expected be more dominant than others. In the case of wet etching mesa isolation, while it presents good electrical performance, this technique does not present the best cell performance obtained in this study. The limiting factors for this technique consist in the isotropic behavior creating a larger sidewall length, as it may become problematic for micro solar cell performance and reliability. The sidewall roughness could not be assessed because of the topography, but it is expected to be smooth, which could explain the good open-circuit voltage obtained. Furthermore, it is important to mention that perimeter effects may not be the same from one subcell to another. Indeed, Espinet-González and coauthors have previously shown that the perimeter recombination of the InGaP and Ge subcells is negligible, whereas the (In)GaAs middle cell dominates the recombination current [Espinet-Gonzalez et al. (2014)].

In the case of saw-dicing isolation, the sidewalls present excellent anisotropy, resulting in a short profile length. However, the combination of a high sidewall roughness with the micro fractures reduces severely the performance. These characteristics represent the limiting factors for this technique and it 
will limit the device performance. In fact, those characteristics will even limit the performance restoration after the wet clean as it will only reduce high spatial frequency roughness down to a lower spatial frequency roughness. Nevertheless, despite a partial performance restoration, the diamond blade damage persists as shown in fig. 6d. The wet clean creates a slight under etching, which increases the sidewall length (fig. 5). However, this mechanism is not dominant since the roughness reduction and the contamination removal seem to be the key to obtain a good performance with such a technique.

Plasma etching enables an anisotropic mesa isolation without micro fractures. These two characteristics are obtained with the combination of the plasma ion-bombardment and chemical etching, resulting in excellent cell performance. Residual plasma damage removal by wet etching has also been reported previously on GaN [Lee et al. (2004)]. While both a short sidewall length and roughness can explain an enhanced performance, a third mechanism is beneficial for the device. The use of hydrogen during the plasma etching process provides a hydrogen-based passivation [de Lafontaine et al. (2021b)], especially in the top cell vicinity that is not etched during the wet clean. While Espinet-González and coauthors have previously shown that the perimeter recombination of the InGaP and Ge subcells is negligible [EspinetGonzalez et al. (2014)], the quality of the InGaP subcell sidewalls may still be improved. The wet clean can further enhance the performance of the plasma etched samples and results in the best photovoltaic performance obtained in this study. It can be explained by the sidewall roughness reduction and the 
chlorine contamination removal [de Lafontaine et al. (2021b)].

However, a few other aspects must be taken into account for an implementation in a production line. More precisely, the isolation trench width must be as small as possible to maximize the active region of the epiwafer area and the process throughput must be as high as possible. To maximize the epiwafer area, plasma etching enables to pattern narrower trenches than the two other techniques, which makes it the preferable technique, especially for micro solar cells. [de Lafontaine et al. (2021a)] Indeed, the dimensions are defined by photolithography and that the etch is highly anisotropic, as shown on fig 4a and 6a. Narrow trenches are not possible with saw-dicing or with the wet etch process because the width is defined by the blade or by the under etching, respectively. For the process throughput, saw-dicing is the fastest process to perform mesa isolation on large devices $\left(>1 \times 1 \mathrm{~cm}^{2}\right)$. [de Lafontaine et al. (2021a)] The main drawback of this method is that it is not parallel. Both wet and plasma etching are parallel processes, which enables to decouple the process time from the device dimension. However, they require an additional lithography step. Plasma etching is performed in a single step whereas the wet etch process is performed in several steps, in several baths. For this reason, the best process throughput for smaller devices $\left(\sim 1 \mathrm{x} 1 \mathrm{~mm}^{2}\right)$ is obtained with plasma etching. Thus, plasma etching + wet clean is not only appealing from a performance standpoint but also in terms of throughput. Another point that needs to be considered is the toolset. Plasma etching requires tools that are not common in solar cell fabrication facilities, which will require initial investments and expert staff 
hiring.

\section{Conclusion}

In conclusion, different mesa isolation techniques were assessed on both the triple junction solar cell open-circuit voltage and the sidewall morphology. Both the sidewall profile length and roughness were assessed. However, it has been shown that to maximize the open-circuit voltage, it is the sidewall roughness that has the largest impact. The sidewall profile length should be as short as possible, which can be obtained with anisotropic processes such as saw-dicing and plasma etching. The sidewall roughness should be minimal, which can be obtained by using wet chemical etching, either by performing a wet etch mesa isolation or performing a post-isolation wet clean. From this study, the best technique seems to be the combination of plasma etching with a wet clean, as it combines all the best characteristics. The combination of ion bombardment and chemical reaction enables a highly anisotropic etch with a minimal sidewall roughness. The anisotropy results in a short sidewall profile length of $\sim 10.5 \mu \mathrm{m}$. The post-isolation wet clean enables to reduce even more the roughness down to a Sdr value below 1.5\%. Plasma etching offers an interesting pathway for multijunction solar cell miniaturization [Albert et al. (2021)]. Despite the fact that this study is focussed on triple junction solar cells, all mesa isolation methods could be relevant for other III-V-based devices such as four, five or six junction solar cells, phototransducers and light-emitting diodes. 


\section{Acknowledgement}

LN2 is a joint International Research Laboratory (IRL 3463) funded and co-operated by Université de Sherbrooke (Canada) and CNRS (France) as well as INSA Lyon, ECL, Université Grenoble Alpes (UGA) as well as the French national nanofabrication network RENATECH. The support from NSERC, Prompt and STACE through the MARS-CPV project is acknowledged. M. de Lafontaine acknowledges FRQNT and Université Grenoble Alpes for financial support.

\section{References}

Albert, P., Jaouad, A., Hamon, G., Volatier, M., Valdivia, C., Deshayes, Y., Hinzer, K., Bechou, L., Aimez, V., Darnon, M., 2021. Miniaturization of ingap/ingaas/ge solar cells for micro-concentrator photovoltaics. Progress in Photovoltaics: Research and Applications 29. doi:10.1002/pip.3421.

Belghachi, A., Khelifi, S., 2006. Modelling of the perimeter recombination effect in gaas-based micro-solar cell. Solar Energy Materials and Solar Cells - SOLAR ENERG MATER SOLAR CELLS 90, 1-14. doi:10.1016/j.solmat.2005.01.009.

Bennett, M.F., González, M., Lumb, M.P., Yakes, M.K., Schmieder, K.J., Tomasulo, S., Abell, J., Meyer, J.R., Walters, R.J., 2015. Development of wet etch processing for inxal1-xasysb1-y solar cells grown on inp, in: 2015 IEEE 42nd Photovoltaic Specialist Conference (PVSC), pp. 1-4. doi:10.1109/PVSC.2015.7356353. 
de Lafontaine, M., Ayari, F., Pargon, E., Gay, G., Petit-Etienne, C., Turala, A., Jaouad, A., Volatier, M., Fafard, S., Aimez, V., Darnon, M., 2021a. Multijunction solar cell mesa isolation: A comparative study. AIP Conference Proceedings 11.

de Lafontaine, M., Pargon, E., Gay, G., Petit-Etienne, C., David, S., Barnes, J.P., Rochat, N., Jaouad, A., Volatier, M., Fafard, S., Aimez, V., Darnon, M., 2021b. Anisotropic and low damage iii-v/ge heterostructure etching for multijunction solar cell fabrication with passivated sidewalls. Micro and Nano Engineering 11, 100083. URL: https://www.sciencedirect.com/science/article/pii/S2590007221000046, doi:https://doi.org/10.1016/j.mne.2021.100083.

Dominguez, C., Jost, N., Askins, S., Victoria, M., Antón, I., 2017. A review of the promises and challenges of micro-concentrator photovoltaics, p. 080003. doi:10.1063/1.5001441.

Espinet-Gonzalez, P., Rey-Stolle, I., Ochoa, M., Algora, C., Garcia, I., Barrigón, E., 2014. Analysis of perimeter recombination in the subcells of gainp/gaas/ge triple-junction solar cells. Progress in Photovoltaics: Research and Applications 23. doi:10.1002/pip.2501.

Fafard, S., 2001. Solar cell with epitaxially grown quantum dot material. URL: https://patents .google.com/patent/US7863516B2/ko. u.S. Patent No. 7,863,516.

Fouchier, M., Pargon, E., Bardet, B., 2013. An atomic force microscopy- 
based method for line edge roughness measurement. Journal of Applied Physics 113. doi:10.1063/1.4794368.

Geisz, J., France, R., Schulte, K., Steiner, M., Norman, A., Guthrey, H., Young, M., Song, T., Moriarty, T., 2020. Six-junction iii-v solar cells with $47.1 \%$ conversion efficiency under 143 suns concentration. Nature Energy 5. doi:10.1038/s41560-020-0598-5.

Helmers, H., Oliva, E., Bronner, W., Frank, D., Bett, A., 2011. Processing techniques for monolithic interconnection of solar cells at wafer level. Electron Devices, IEEE Transactions on 57, 3355 - 3360. doi:10.1109/TED.2010.2076190.

Kim, Y., Kim, K., Kim, T.W., Mawst, L.J., Kuech, T.F., Kim, C.Z., Park, W.K., Lee, J., 2014. Ingaasnsb/ge double-junction solar cells grown by metalorganic chemical vapor deposition. Solar Energy 102, 126-130. URL: https://www.sciencedirect.com/science/article/pii/S0038092X14000371, doi:https://doi.org/10.1016/j.solener.2014.01.019.

de Lafontaine, M., Darnon, M., Jaouad, A., Albert, P., Bouzazi, B., Colin, C., Volatier, M., Fafard, S., Arès, R., Aimez, V., 2016. Plasma etching applications in concentrated photovoltaic cell fabrication. AIP Conference Proceedings 1766, 060001. URL: https://aip.scitation.org/doi/abs/10.1063/1.4962091, doi:10.1063/1.4962091, arXiv:https://aip.scitation.org/doi/pdf/10.1063/1.4962091.

Lafontaine, M., Pargon, E., Petit-Etienne, C., Gay, G., Jaouad, A., Gour, M.J., Volatier, M., Fafard, S., Aimez, V., Darnon, M., 2019. Influence of 
plasma process on iii-v/ge multijunction solar cell via etching. Solar Energy Materials and Solar Cells 195, 49-54. doi:10.1016/j.solmat.2019.01.048.

Lee, J.M., Lee, K.S., Park, S.J., 2004. Removal of dry etch damage in p-type gan by wet etching of sacrificial oxide layer. Journal of Vacuum Science \& Technology B: Microelectronics and Nanometer Structures Processing, Measurement, and Phenomena 22, 479-482. URL: https://avs.scitation.org/doi/abs/10.1116/1.1645880, doi:10.1116/1.1645880, arXiv:https://avs .scitation.org/doi/pdf/10.1116/1 .1645880.

Malevskaya, A., Il'inskaya, N., Andreev, V., 2019. Developing methods for wet chemical etching of a separation mesa structure during creation of multijunction solar cells. Technical Physics Letters 45, 1230-1232. doi:10.1134/S1063785019120241.

Raappana, M., Koikkalainen, T., Polojärvi, V., Aho, A., Aho, T., Isoaho, R., Tukiainen, A., Guina, M., 2021. Nonselective etching of as and p based iii-v solar cell heterostructures with aqueous solutions of hio3 and hcl. Solar Energy Materials and Solar Cells 226, 111097. URL: https://www.sciencedirect. com/science/article/pii/S0927024821001380, doi:https://doi.org/10.1016/j.solmat.2021.111097.

Turala, A., Jaouad, A., Masson, D., Fafard, S., Arès, R., Aimez, V., 2013. Isolation of iii-v/ge multijunction solar cells by wet etching. International Journal of Photoenergy 2013. doi:10.1155/2013/583867.

Wiesenfarth, M., Steiner, M., Helmers, H., Bett, A., 2020. Voltage losses due to the perimeter and dark area in micro-concentrator 
solar cells. Solar Energy Materials and Solar Cells 219, 110791. doi:10.1016/j.solmat.2020.110791. 